Página inicial: 419 - Página final: 435

TIPO DE ARTÍCULO: de Investigación

\title{
CONFLICTOS SOCIALES Y COYUNTURA DE PAZ EN COLOMBIA. DECADENCIA OCCIDENTAL Y POTENCIALIDAD DEL LATINOAMERICANISMO.
}

\author{
SOCIAL CONFLICTS AND SITUATION OF PEACE IN COLOMBIA: WESTERN \\ DECADENCE AND POTENTIALITY OF LATIN AMERICANISM.
}

Recibido: Enero 2014 Revisado: Marzo 2014 Aceptado: 1 de Mayo 2014

Por: Edison Villa Holguín ${ }^{1}$, Alfonso Insuasty Rodriguez ${ }^{2}$.

\section{RESUMEN.}

Si bien el conflicto armado interno parece haber llegado a un punto crítico, abriéndose espacio una importante negociación del conflicto armado interno que lleva más de 50 años, entre las Farc-Ep y el Gobierno de Colombia, es necesario ahondar en torno al papel de la participación de la población, quienes de manera real, expanden y complejizan los antagonismos; es el pueblo quien en últimas demostrarán la capacidad para promocionar y consolidar el cambio, pues si así no se asume, las actuales negociaciones no redundará en un cambio real, iniciándose otros ciclos de guerra, la profundización de los conflictos territoriales, ambientales, sociales, económicos, políticos, como ya ha ocurrido en la dolorosa historia de Colombia.

\section{PALABRAS CLAVE.}

conflicto armado interno, paz, solución política, participación, movimiento social y popular.

\section{ABSTRACT.}

Even though the armed conflict seems to have reached a critical point, opening up space an important negotiation of the internal armed conflict that takes more than 50 years, between the FARC-EP and the Colombian government, it is necessary to deepen around the role of the participation of the population, who in a real way expand and make antagonisms complex, it is the people who ultimately will demonstrate the ability to promote and to consolidate the shift, because if it is not thus assumed, the current negotiations will not redound to a real change, where other cycles of war take place, the deepening of the territorial, environmental, social, economic, political conflicts, as it has already happened in the painful history of Colombia.

\section{KEY WORDS.}

Internal Armed Conflict; Peace; Political Solution; Participation, and Social and Popular Movement.

\footnotetext{
${ }^{1}$ Magister en Educación, educador popular, activista social, cursa estudios Doctorales en el Ipecal (México). Docente investigador, integrante del grupo de investigación Gidpad de la Universidad de San Buenaventura Medellín. Medellín Colombia. Contacto: evilla@elpoli.edu.co interandinos@yahoo.es.

${ }^{2}$ Licenciado en filosofía, Abogado, Especialista en ciencias Políticas, adelanta Estudios Doctorales en el Ipecal (México). Docente investigador, director grupo de investigación Gidpad y Editor de la Revista El Ágora USB, de la Universidad de San Buenaventura Medellín. Integrante del grupo Autónomo de Investigación para la transformación Kavilando. Medellín, Colombia. Contacto: Alfonso.insuasty@usbmed.edu.co
} 


\section{Introducción.}

La ilegitimidad de la institución Estado Nación o Estado Moderno la aceleró la economía globalizada, aunque el agotamiento de su racionalidad constitutiva ya venía en jaque, pues las perspectivas criticas a la politica ilustrada y los grandes debates politicos de los siglos XIX y XX visualizaron las relaciones de dominación promovidas tanto por el capital y el absolutismo científico, como por la idea de progreso antropocéntrica y el arquetipo patriarcal, de manera que una nueva politica no es sustentable desde un proyecto ilustrado que promueve las relaciones de dominación.

Hoy el debate político, plantea desafiar el pensamiento y la teoría política clásica, en la búsqueda de otros proyectos de sociedad para el siglo XXI.

\section{La crisis del estado moderno hoy, se puede evidenciar principalmente por:}

- La imposibilidad de resolver los problemas profundos de lo humano desde el equilibrio igualdad-libertad y

- La omisión a un trámite adecuado de las problemáticas sociales, situaciones que le hacen inviable e ilegitimo.

- La falacia del partidismo que de fondo se sostiene en el pensamiento único y la delegación del poder y de las decisiones de los estados-nación al reduccionismo del tecnicismo económico internacional.

- Algunos análisis contemporáneos asumen que la sociedad occidental estállegando a los límites de su racionalidad en términos de modelo de administración política. Tal modelo administrativo es el responsable además de la no regulación, y la no reparación de los desastres ambientales de los últimos siglos, al convertirse en el instrumento jurídico y el gran custodio formal del capital. Modo de producción dirigido por autómatas, donde parece no hay lugar para que los sujetos se retracten o se retroalimenten frente a las situaciones inhumanas que genera su caduco funcionalismo.

- La democracia tal como se vive hoy agudiza el contexto de dominación e injusticia. Las evidencias sobre la falta de legitimidad de los sistemas politicos anteriores y vigentes, acuñados en Latinoamérica sobran.

La institucionalidad en cualquiera de sus modalidades no ha sido el espacio para tramitar las contradicciones del propio sistema, los aparatos legales no pueden resolver las demandas y deudas sociales e históricas; es así que, las ataduras radicalizadas en el capital, el empresarismo financista externo e interno, el poder militar y el beneficio privado no le permiten tramitar los problemas concretos y comunes de las mayorias con la población.

Durante el siglo XX la iglesia y el estado nación dieron paso a las hegemonias globales presentes, al quedar caducos como formatos o lugares para tramitar la complejidad de conflictos socioculturales e históricos generados por la linealidad del progreso occidental. Hoy nuevas institucionalidades hacen relevo de gobierno, y es el comercio a gran escala y las redes informacionales, es decir el mercado y los medios masivos de información, quienes hacen creer que los bienes comunes y las garantías para la vida, nombradas como derechos humanos, pueden llevarse a cabo 
como servicios comerciales, sí y solo sí operan en grandes centros administrativos, ambientados en la plataforma tecnológica del sistema bursátil, lo que se conoce como capitalismo financiero, dándose así lugar a la nueva infraestructura que termina disponiendo de los espacios y tiempos de las poblaciones humanas.

Lo que hoy se ve, es que cada vez, en más lugares, el estado-nación ha delegado a la ley de mercado su administración, el testimonio personal y la vivencia colectiva nos demuestra que las politicas neoliberales no están hechas para resolver los problemas, sino para provocarlos o exacerbarlos, en su ánimo de concentración de fuentes y medios de energía, que es la clave que mueve hoy las redes de acumulación de poder desde donde se intenciona el sistema de economía global. (Restrepo Dominguez, 2014)

El neoliberalismo se ha escondido en la infraestructura tecnológica y aparece como invisible a la cotidianidad de las gentes. El poder concentrado asume la investidura del consumo y ese giro tiene como consecuencia la aceleración de la cosificación y mercantilización de la vida y la diversidad.

De esta forma la crisis civilizatoria en la que ha quedado la sociedad después de padecer el trámite capitalista se vuelve crónica. El valor de la vida y la colectividad pasaron de moda y la búsqueda de movilidad social hacia el pensamiento burgués, a como dé lugar, ha llevado al individualismo, al mercenarismo, a la competencia por surgir desde el tener y el mercadeo o la cosificación de las personas, expresiones contundentes de las causas estructurales de los conflictos sociales y políticos de la época. Lo que hace entender que en este presente de conflictividad, diversos pueblos Latinoamericanos al calor de actitudes politicas comunitarias y la activación de valores hacia una democracia radical para otra sociedad posible, se enfoquen desde otras tramas culturales y otras ideas de progreso que vienen en construcción en los territorios de la región, buscando acuerdos locales y nacionales de regulación ética para la interacción en el comercio internacional. Asumiendo que son los pobladores quienes deben regular a sus gobiernos y que este cometido se logra recreando la movilización de la masa crítica que proyecta conveniencia común y buen vivir. (Zibechi, 2000)

Para el caso de Colombia, se hace relevante superar como sociedad la histórica represión que se ha hecho sobre las utopías que buscan el bien mayoritario, la identidad cultural endógena, la colectividad del territorio, la distribución de la productividad y la vida digna para toda la población. En los últimos 50 años, dicha represión se ha llevado a cabo con dispositivos simbólicos y, de hecho, institucionales y para-institucionales, con estrategias como la estigmatización, la persecución, la eliminación, la desaparición y todas las demás formas de violencia política aplicada en los territorios nacionales contra los proyectos politicos de diferencia y antagonismo a las hegemonias históricas.

En el presente se plantea un ambiente de negociación entre quienes han ostentado el poder institucional y quienes desde la insurgencia reclaman derechos politicos y económicos, pero en este intento de superación de la exclusión social y política es necesario buscar mecanismos de participación colectivos, alternativos y directos con la población, que logren intervenir las causas sociales de la guerra, la reparación 
de los daños a los tejidos humanos fracturados, la superación de los odios a lo diferente de manera politica, buscando se transformen las politicas que garanticen el derecho a la memoria histórica y la no repetición. (Insuasty Rodriguez \& Vallejo Duque, Crar Ambiente para la Paz, 2012)

\section{Metodologia.}

Se realizó un estudio histórico, analítico - hermenéutico, para al cuál le antecedió un rastreo documental, la contratación de fuentes, rastreo de fuentes institucionales y no institucionales; luego de este rastreo documental se contrastaron algunas hipótesis en varios escenarios de discusión y debate con académicos y actores especializados en el marco de la temática abordada, lo que permitió contrastar la información, generar rutas de análisis y encontrar elementos para el debate.

\section{Resultados.}

Los debates vigentes sobre el pensamiento político contemporáneo.

El Modelo civilizatorio vigente además de degradaciones naturales y materiales, produce una humanidad decadente en términos éticos e intelectuales. La visión fragmentada de la educación tecnicista, especializada y cientificista en el paradigma positivista, ha hecho de los estudios politicos, sociológicos y humanistas, comprobadores de verdades hipotetizadas y prescriptivas. Parece que la filosofia del derecho, las perspectivas éticas y científicas, no necesariamente permiten ver la realidad de los problemas a los que se está enfrentando la humanidad y que conduce a la ceguera de la inteligencia de la sociedad contemporánea. En las academias contemporáneas está ausente pensar el presente y repensar la política. (Morin 1998) y por ende a quienes como actores sociales hacen parte de la intelectualidad formal les queda dificil cuestionar los limites de la economía globalizada. (Vega Cantor, Crisis civilizatoria, 2009)

El presente instituye la complejidad politica y el sistema más cercano a ello es el democrático llevado a fondo. Asunto que aún no pasa. Si se entiende éste como la reglas del juego que permite que la múltiple diversidad de opiniones se exprese, se confronte y coexista a través de la polémica, de la discusión y de la dialéctica del consenso y el disenso Me(Morin, Civilización, 1998). Un renacimiento politico para hoy implica que la vida en diversidad cultural sea el fundamento de la democracia, Además de inscribir los problemas dentro de la comprensión de la política multidimensional que interprete el desarrollo de los seres humanos y los fenómenos que se producen entre ellos.

En la antigüedad, se asumía que los dioses inspiraban y representaban una serie de prescripciones y principios trascendentes, como fundamentos de la vida política. E1 orden político oficial era delegado a quienes tenían las facultades para interpretar y actuar como los dioses deseaban. En occidente las monarquías y el papado romano asumian tal papel. La modernidad inaugura una nueva época, donde la razón humana está llamada a remplazar las inspiraciones de lo sacro, asumiéndose como el fundamento de regímenes políticos muy concretos. La modernidad se convierte 
así en el proyecto socio-político que surge del ejercicio intelectual de deliberación, que como fruto de la razón fue consolidándose en un pacto político nombrado como contrato social, que termina dando legitimidad a los regimenes occidentales hasta la contemporaneidad. Absolutismo, revoluciones burguesas y democracias liberales.

Por medios ilustrados y por obra y gracia de la intelectualidad burguesa, entre los siglos XVII y XVIII, los ciudadanos europeos y quienes en el mundo pensaban como ellos, contrataron un pacto político bajo el que pretendieron que el destino de su sociedad quedara en manos de ella misma, fundando el hito idealista de una cultura cívica, democrática y una sociedad igualitaria de compromiso común. Como resultado de la revolución francesa se manifiesta la promesa de garantías de libertad y trato en igualdad y fraternidad, por parte del formato y el compromiso y la sujeción a la ley por parte de la sociedad civil.

El estado occidental se convierte así en la figura que el pensamiento del siglo XVIII perfecciona, como la institución que encarna los fines comunes de sus asociados, según el pacto celebrado y al que los socios se atienen. Estas aspiraciones fruto del pensar de la humanidad ilustrada que recogió las tensiones y conflictividades de la época, produjo la sociedad ideal del consenso, con intereses altruistas y nobles, pero cuyo desarrollo histórico por lo artificioso y ficcionado terminó siendo el pretexto para imponer una racionalidad única, blanca, burguesa, masculina, antropocéntrica y prescrita entendida como la vía política correcta.

Un siglo después, nace una segunda versión del contrato, configurando un estado restringido, sometido a los desafios del industrialismo, sustentado en el derecho que preserva y garantiza la autonomía del individuo, pero solo en lo que tiene que ver con la participación en el mercado. La revolución industrial termina transformando el contrato social y sus principios de igualdad y libertad en el marco del derecho privado, reviviendo el modelo de sociedad prescrita, pero esta vez el dios capital lo decide todo. La modernidad como deseo teórico y filosófico ilustrado, al confrontarse con la realidad construida por el modo de producción que se consolidó en el siglo XIX, termina siendo instrumentalizada, por la dinámica capitalista, que modificó los acuerdos del pacto original, asumiendo la orientación del orden político y social. Ya desde el siglo XIX, se entendía que el libre mercado destruiría el orden social contractualista sin generar uno nuevo. La conciencia social empieza a reconocer que la pobreza, la pauperización, la degradación y la miseria no son desgracias naturales, ni divinas, ni son fenómenos auto-causados, sino causados por el propio desenvolvimiento económico. Desde entonces las políticas de la economía internacional son consideradas las generadoras de la agudización de las problemáticas del desencanto humano.

El reclamo generalizado al contrato incumplido hace emerger nuevas vertientes económico-politicas preocupadas por la cuestión social. Desde la crítica y la presión de las luchas sociales, se crea en occidente un espacio político que deriva en derechos y deberes entre la sociedad, el estado y el mercado. El liberalismo solidario, aparece como corriente de bienestar y el aparato se compromete en reasumir la responsabilidad social por los menos favorecidos. 
Las concepciones de equilibrio desde la racionalidad del crecer y redistribuir terminaron por moldear las instituciones para que las corrientes de la justicia social y desarrollo del capitalismo se mantengan paralelamente, haciendo del estado una tercería que media entre los capitalistas y los obreros asalariados para buscar la redistribución de la riqueza y el beneficio social, el estado intervino la economía y asume la dirección del pacto social, lo que se llamó estado bienestar o keynesianismo en honor a su gestor Keynes en 1929.

El estado bienestar se perfiló como una transición a la dinámica de desconcentración de la riqueza, la explotación y la injusticia hacia las clases trabajadoras por parte de la producción en serie y en masa, del fordismo y luego el taylorismo en la lógica de sobre-producir. Pero para los capitalistas los negocios no son rentables si el estado los regula y temiendo la concentración de la riqueza por parte del estado nación, se procedió al desmonte de las pocas garantías del bienestar social y el ajuste y reformulación del estado desde la doctrina neoliberal.

El neoliberalismo se convierte en el fin del estado nación. La dinámica del capital cuestiona el pacto original y no lo cumple. Los programas sociales y las garantias laborales acordadas entre capitalistas y obreros a través del estado se vinieron abajo y reapareció el predominio de formas centralizadas de dominación y la regulación solo por parte de la ley del mercado. Los recursos, los bienes y las riquezas no son ya de la nación, que no administra, ni redistribuye autónomamente, son de la economía global. El estado ya sin nación se vuelve una figura de regulación y arbitraje. (De Sousa Santos, 2000)

Se genera un escenario nebuloso entre estado y mercado. El neoliberalismo restringe y desarticula el contracto pre-existente. Esa retracción del estado hace que el contracto sea entre individuos, no con el estado. La economía es asumida totalmente por del régimen privado. Las constituciones se vuelven códigos de comercio y el estado es reducido a su minima expresión, limitado margen de maniobra que tiene que ver con el control del orden público en el territorio. El mercado expulsa y el estado deja de brindar protección. Se consolida así la disgregación, la marginalidad, la exclusión, el desempleo, la crisis de los sistemas de seguridad social y la decadencia de las instituciones en todo el mundo. (Rodriguez Dominguez, 2014)

Pero la lectura de la realidad y del contexto político actual, implica incluir en los análisis además de lo que se ve desde los padecimientos sociales y que se nombra como consecuencias, lo que normalmente no consideramos o normalizamos, las causas. Riqueza concentrada, individualismo y competencia por los recursos, que se fundamentan en un esquema de relación sustentado en el capital.

Se requiere hoy una politica que sea conciente de las relaciones entre los seres humanos y de su naturaleza social. La multidimensionalidad de la dinámica social implica otra lectura de realidad y para ello se necesita entre otras claves considerar la transformación de la matriz de pensamiento de prescripción y fragmentación teórica racionalista, por un pensamiento capaz de recoger el desafio de la complejidad, capaz de contextualizar, de globalizar, de relacionar lo que está separado, basado en la conciencia planetaria de degradación generada por la producción humana. 
A las problemáticas vigentes de la especie, las leyes del mercado empiezan a ser confrontadas por los principios cívicos. Los movimientos sociales de resistencia local y global, asumen con fuerza el debate de la vida asociativa, resignificando los componentes de la solidaridad y los derechos económicos, sociales y culturales como pueblos, desde la búsqueda por la responsabilidad del estado y la intervención del capital en el deterioro de vida y de las relaciones intersubjetivas. Al ir caminando por un horizonte político diferente e ir explorando por las autonomías políticas, los ejercicios de contradicción siguen perfilando y asimilando procesos antisistémicos y transfronterizos que van emergiendo en las organizaciones comunitarias y los movimientos populares. (Zibechi, 2000)

Como actores críticos de la modernidad las luchas del sur global van enfocando el sentido de sus resistencias como movimientos sociales, como una de ellas, el enfrentamiento político al sistema global de economia y a las burocracias locales que la administran, entendiendo que éstas no definen directamente el guión, pero que sí intervienen en su aplicación. La transformación de la sociedad no solo se logra luchando por ganar en infraestructura, a la par implica que se incida en la cultura, es en ella donde está la potencialidad transformadora, pues los cambios profundos en la súper estructura implican deconstruir las prácticas habituales. Situación que se hace concreta al considerar mutaciones de fondo en las actitudes frente a los dogmas religiosos y científicos, al desarrollo industrial, al progreso capitalista, al consumo masivo, a las relaciones humanas de dominación, a las relaciones con la naturaleza y en general a las concepciones sobre los proyectos de vida y sociedad. (Boff, La gestación del pueblo brasilero, la universidad y el saber popular, 2014)

Al calor de la organización comunitaria se aprende que los problemas socioculturales y de civilización no se resuelven solo pidiendo reformas economicistas a la recurrencia neoliberal, sino que se hace necesario regenerar y reconfigurar el tejido humano social y cultural hacia una política de otra civilización. La participación y la democracia empiezan a ser asumidas de otras maneras. La marginalidad hacia las formas hegemónicas desde el autonomismo y la contracultura adquiere sentido de resistencia, convirtiéndose en acontecimiento político en formato crítico, que expresa intenciones de otros poderes, generando los canales y los argumentos a través de los cuales se difundirán y construirán los nuevos valores para la nueva sociedad. (Insuasty Rodriguez, Solos no podemos. Editorial, 2010)

Este trayecto de 400 años de adaptación al capital como fundamento relacional del sujeto moderno concreto, matriz de racionalidad desde la cual se piensa y se actúa cultural y políticamente en occidente, ha dejado preguntas que agudizan las problemáticas de vida común y de construcción de otra sociedad y cuya respuesta buscamos en el giro de pensamiento que supera la condición relacional del capital: ¿Es vigente pensar un pacto universal de deliberación humana? ¿Los órdenes políticos solo puede ser producto de la ilustración de los sujetos? ¿Cómo tramitar la tensión de la conciencia ilustrada de inclusión -exclusión en la construcción de sociedad democrática? ¿Las politicas del orden democrático podrán superar las relaciones de producción depredadoras, hacia un modelo eco-sistémico sustentable? 


\section{El giro latinoamericano}

La muerte de los paradigmas de salvación universal que mantenian en jaque el siglo XX, generan como posibilidad la visualización y reconocimiento del camino paralelo emprendido en la construcción de otras formas políticas, en otros pueblos y en otras sociedades, algunas presentes en la gran y diversa Latinoamérica que se construye desde el discontinuo reclamo de la subalternidad hacia la sonoridad de la voz de los proyectos de emancipación. (Restrepo Marin, 2013)

Las geo-estrategias de la politica imperial de los siglos XIX y XX, obstaculizaron los propios desarrollos en la región, y determinaron las categorias universales con las que los pueblos Latinoamericanos tendrian que pensarse, sin ser consideradas sus condiciones sociales y culturales. La decadencia del modelo estatal de occidente, no tendría por qué presentarse como "universal" y los demás pueblos del mundo no estarian obligados a asumirlo, a no ser por el chantaje comercial de los banqueros del norte, perpetuándose así la sistemática linealidad desarrollista, que como herencia colonial, se ha convertido en una de las variables constituyentes del belicismo político y la violencia estructural e histórica del mundo y en especial de la región. Por ende los ritmos y los tiempos que trajo Europa no son habituales, son condicionados y presionados por la productividad occidental. Los ritmos en Latinoamérica para construirse y pensarse han sido siempre otros, de allí que para el norte seamos entendidos como sociedades disfuncionales o estados subdesarrollados. (Vega Cantor, Colombia y geopolicia hoy., 2013)

La modernidad como camino trazado desde el colonialismo y el desencanto ante la promesa incumplida del desarrollismo, reprodujo la dependencia económica, además del instrumentalismo estatal y generó las problemáticas de gobernabilidad de "seudo-democracia" que caracterizan a la región, y con las cuales se transita en la esperanza de vientos de cambio, que implique que nuestra América, se sacuda decidiendo un propio rumbo.

En los últimos 30 años, se dejan entrever cambios políticos de cuenta de los logros de los movimientos socio-históricos, que con sus demandas y reivindicaciones colectivas han aportado a visualizar los profundos cuestionamientos sobre el devenir de la vida humana y la diversidad, lo mismo que con sus proyecciones y acciones de recuperación endógenas y territoriales.

El análisis de la acción colectiva desde la construcción y las luchas de los movimientos latinoamericanos, deja ver que no todas las posibilidades de cambio político para la región se encuentran ancladas en la ilustración del norte o en lo que seguiría de ella. Los pueblos de Latinoamérica se están redescubriendo así mismos como a-modernos. El proyecto del buen vivir de pueblos andinos como Bolivia y Ecuador así lo hacen entender. No como gestas de unos gobernantes, sino como la proposición, el compromiso identitario y el respaldo comunitario que hay detrás de ello. (Zibechi, 2000)

En el presente, Uruguay y Cuba en sus transformaciones internas, cada una en su momento y en su realidad contextual, con autonomía, soberanía y en coherencia como pueblos, avalan proyectos ético-políticos que dan ejemplo de cultura política, 
de real y concreto mundialismo y se van convirtiendo en referentes de humanismo integral, al irse ocupando de las incertidumbres y contradicciones heredadas de dos de los tres viejos principios del contrato liberal, la igualdad y la libertad. Abordándoles y desarrollándoles de acuerdo al contexto propio y a las propias capacidades, generando así procesos sustentables de sociedad colectiva, donde el individualismo y el beneficio privado se regulan.

En la invisibilidad histórica caminan también diversidad de procesos comunitarios Latinoamericanos que no buscan ni operan en el poder del estado-nación, y en sus territorios construyen poder y avanzan en democracia radical como otros proyectos de sociedad, al proponer la propia coyuntura, dando el paso a las preguntas por la conservación de la especie cambiando la escala del paradigma político del desarrollo occidental (Morín 1985) y su globalización económica.

En febrero de 1984, multitudes de campesinos brasileros vienen desapropiando tierras, donde se asientan y crean comunidades de trabajo y de vida. En el presente, a partir de su cuarta cumbre, luchan por un nuevo proyecto, que "necesita ser construido con todas las fuerzas populares, volcadas para atender a los intereses del pueblo" planteándole una nueva tarea al proyecto: "una reforma agraria que tiene como base la democratización de la tierra, buscando producir alimentos saludables para toda la población". (Movimiento de los Trabajadores Rurales sin Tierra, 2013).

Más hacia el noroccidente de la región, los pueblos indigenas Zapatistas de Chiapas, en enero de 1994, le plantean al mundo un nuevo desafio: "El mundo que queremos es uno donde quepan muchos mundos. La patria que construimos es una donde quepan todos los pueblos y sus lenguas, que todos los pasos la caminen, que todos la rían, que la amanezcan todos.” (Monsivais \& Poniatowska, 1997).

Algunas naciones como Argentina, Venezuela y varios países centroamericanos, viven la tensión de la trasformación en soberanía en la tarea de replantear su propio modelo económico, no por uno sostenible sino en la búsqueda de un desarrollo sustentable para el ecosistema y hacia una civilización soportable, aprendiendo de los muchos pueblos anónimos y de numerosos movimientos sociales latinoamericanos que ponen en marcha su lucha por nuevas visiones y prácticas de ciudadanía, democracia, relaciones sociales y desarrollo.

Se reconoce así el potencial de políticas culturales en la promoción de transformaciones sociales, a partir de la ruptura del discurso único neoliberal y de resistencia a los proyectos de dominación contemporáneos (Escobar, Alvarez, \& Dagnino, 2001). Y hoy vemos que la mitad de Latinoamérica empieza a tener mejores conflictos con luchas por la democracia propias del cambio de proyecto. (Boron, 2004) Pensándose y siendo para sí, conflictuada en su internalidad política por querer rehacerse a sí misma, desde ella misma, como sociedad de todos los colores, aprendiendo a reconocer la pluralidad de espacios politicos y la multiplicidad de posiciones antagónicas.

En ese recambio de los términos de los debates políticos y socio-económicos sobre el escenario potencial de pensamiento transformador latinoamericano, quedan 
tareas en formato de interrogantes: ¿Cómo la fuerza orgánica de los movimientos sociales y comunitarios puede fijar las reglas en el sistema económico internacional? ¿Alcanza la legitimidad y la dignidad de los movimientos para fundar otros ordenes políticos?

$\underline{\text { Los intentos de construcción de sociedad en medio de la guerra. El caso Colombia. }}$

Ubicados en el punto de mirada del germen del conflicto o sus causas estructurales, queriendo entender lo que nos acontece como sociedad contemporánea en la dicotomía guerra y paz, para construir una lectura a la realidad de los conflictos sociopolíticos en el país, se reconoce hoy a bajo volumen que las contiendas contemporáneas dentro de la sociedad colombiana tienen rezagos de conflictos anteriores, que permanecen y reactivan, en la conservación de los turnos y las pugnas por la cúspide de la pirámide clásica entre latifundistas, mercaderes, rentistas y leguleyos con maquinaria, fuerza armada y clientela para decretar, titular y administrar justicia a su beneficio en los territorios.

El lugar geopolítico que hoy llamamos Colombia, es un producto construido al calor del combate, nace en medio del hito independentista del siglo XIX y su historia de consolidación como país, se ha dado a partir de confrontaciones regionales y nacionales entre grupos hegemónicos, que se turnan para mantener y custodiar intereses y privilegios a partir de la figura de poder del estado occidental. Se hace crucial reconocer que la historia politica del país es un proceso complejo y constante de tensión bélica que aparece en todos los momentos desde su construcción, en la defensa de los bienes comunes o en la disputa por el poder y las decisiones de las castas de privilegio. En la lógica de esas disputas, se ha monopolizado el estado nación y el relato hegemónico que recae sobre él. (Borda, Umaña, \& Guzman, 2012). Pero como costumbre historiográfica, se nos ha remitido "al tiempo de la violencia en Colombia" como el referente de la conflictividad política en la década de los 40 s y 50 s.

Nuestra historia como pueblo no está hecha propiamente de las gestas épicas de los próceres de la hegemonía presidencialista, ni del instrumentalismo económico que ha difundido y mitificado una versión, haciendo creer a las gentes como suyas, las realidades de progreso y prosperidad de la minoría ilustrada en las reglas de juego impuestas a sangre y fuego por la economía nacional e internacional. Los desplazamientos forzados, los despojos a las comunidades rurales y un sin número de contiendas bélicas no necesariamente registradas por la narración oficial, generan gran parte de la historia de Colombia que hoy vivenciamos en el cotidiano sin la reflexividad que merece. (Vega Cantor, Colombia y geopolicia hoy., 2013)

Para la óptica desde abajo, el relato de la historia oficialista se ha enfocado en los antagonistas de las mayorias poblacionales que justifican sus guerras y pugnas del pensamiento burgués bajo el pretexto por alcanzar el desarrollo económico y consolidar la débil democracia, tratando de desaparecer del mapa la versión de las luchas, contradicciones y aportes, de los demás pobladores, desconociendo los procesos históricos y las particularidades que se van reconfigurando en el dia a dia, en el habitad de las luchas por subsistir en las urbes, por insistir desde el arraigo a una cultura agrícola que provee el alimento a la población y por rechazar 
las practicas injustas, indignas e inhumanas de la política del capital, donde está construyéndose parte de la historia real de la población.

Esta conflictividad, surge y toma forma en las condiciones económico-politicas y socioculturales del territorio, porque más que la construcción de una nación, se ha tratado de imponer un estado, en un trayecto de 200 años de aconductamiento al formalismo republicano, forzando a que su politica, economía y cultura sea revestida con el traje europeo del siglo XIX, es decir la fantasmal democracia del pensamiento burgués, que está fuera de la propia lógica de construcción en el territorio.

Justamente fue el supuesto bipartidismo hegemónico en torno a un proyecto de unidad, de formato clásico de derecha dictatorial, lo que genera el real conflicto de exclusión social y politica, legalizado en el decreto elitista del frente nacional en 1958. Una manera de acabar con las guerras entre hegemonías, se convierte en detonante de la guerra de los últimos 50 años. Parece que nuestra sociedad se ha quedado congelada en la Colombia del bipartidismo, éste no ha sido resignificando, ni colectivizado como memoria acumulada y conciente que garantice no repetición. Se cae históricamente en la trampa del unanimismo que oculta las otras historias y los complejos y profundos conflictos que nos habitan como sociedad.

Se interpreta que las pugnas y confrontaciones violentas de las hegemonías ocultaron los padecimientos de la otredad, que es mayoría y que pasa como "invisible". La situación generada por los sistemas morales del patriarcado que han marginado, oprimido y dominado los cuerpos y las vidas de las mujeres obstaculizando su participación política y social, los dolores del holocausto de los seres originarios en la lucha por el reconocimiento cultural y de la tierra, los de las culturas africanas, en lucha contra la segregación y el esclavismo, los de las personas de los campos, formas culturales colectivas y subjetividades construidas históricamente con base en el arraigo con el territorio y la producción de alimentos básicos y necesarios para sostener la vida, a partir de relaciones armónicas con la naturaleza, que se resiste a desprenderse de su arraigo cultural y en esa resistencia de permanencia organizativa para no dejarse despojar. Es dicha mayoría poblacional quien termina padeciendo la guerra, o a quien le terminan haciendo violencia.

La guerra política de los últimos 50 años fue fruto de un acumulado histórico de conflictos sociales y políticos que podríamos agrupar en tres categorias: los no reconocidos y no asumidos: Situaciones culturales, étnicas, de género y diversidad; los reconocidos y no resueltos: la problemática socio-económica, como la tenencia de tierra y los problemas del campesinado, los pliegos del sector obrero, lo educativo, el empleo, la salud y la vivienda de las mayorias; y los "resueltos" de forma dictatorial: los acuerdos bipartidistas, que solucionó parcialmente la disputa entre grupos hegemónicos de derecha por el mantenimiento del gobierno de régimen presidencialista y el desmonte del estado bienestar. (García, 1977)

Estas últimas actuaciones políticas, generaron a su vez otros ciclos de violencia, como la no participación política de sectores que no sean las elites históricas, lo que se concretó con la alianza macabra en un "frente nacional", que obstaculizó la participación electoral de otras fuerzas y la eliminación física del opositor político de izquierda, caudillos populares, partidos y movimientos políticos como la Unión 
Patriótica, los comités cívicos y las organizaciones populares. Estas problemáticas pululan hoy en la contemporaneidad y en este panorama las venas abiertas claman por justicia, equidad y vida digna, lo que se ha posicionado como la paz de los pueblos, con verdad, justicia y reparación a las víctimas.

Avanzar en cultura política implicará considerar los diferentes matices que giran en torno a la guerra como acontecimiento histórico reprochable, ubicando los cambiantes contextos históricos, abriendo los debates en la sociedad en general sobre la necesidad de reconocer las intenciones con las que se instrumentalizan tanto la contienda belicista y la adecuación "a la fuerza" a procesos socio-económicos prescritos para que el sistema funcione. Entender a profundidad la presente guerra política, está condicionado por ubicar las perspectivas y los puntos de vista de los actores en contienda, cuyos complejos propósitos están hechos de particulares características y trasfondos ideológicos intocables. Se dice que se ha hecho para conservar "la democracia formal" o para modificar la estructura socio-económica y así "alcanzar la democracia radical". Lo cierto es que la guerra la hace la hegemonía utilizando el aparato estatal y una parte del pueblo que no se somete y prefiere alzarse en armas.

Grandes intereses nacionales y globales han aprovechado las circunstancias de la contienda para adaptar el modelo económico local a la economía de guerra y a las condiciones de exigencia del mercado internacional. En sus inicios como coletazo de la guerra fría y de temor occidental al socialismo latinoamericano: la alianza para el progreso, las politicas de la dependencia y el desmonte del estado bienestar. Y en el último tiempo la guerra "anti-narco-terrorista" como apoyo a la doctrina militar de seguridad nacional norteamericana: la Escuela de las Américas y la cooperación en instrucción militar y paramilitar contrainsurgente. Además de una gran cantidad de empresas de especuladores de la guerra, contratistas y contrabandistas de armamento y escuelas multinacionales de mercenarios. (Vega Cantor, Crisis civilizatoria, 2009)

La guerra interna en el modelo neoliberal acrecienta la violencia estructural con el aceleramiento de reformas económicas y jurídicas sobre el territorio que nos hizo vivir en menos de 60 años, 400 años de adaptación capitalista para darle la talla al sostenimiento del norte del mundo. En las últimas décadas la guerra ha sido el escenario perfecto para la adaptación a la economía global. Las condiciones de exigencia del mercado internacional implico un cambio en el modelo de desarrollo y por ende cambios de los usos del suelo, en las despensas de alimentos y materias primas para el neo-extractivismo y la agroindustria a gran escala. Tales exigencias del orden de la intervención económico-cultural se han cumplido a partir de fuerza estatal militar y paramilitar, arremetida que ha desencadenado fenómenos sociales inhumanos como las matanzas, la desaparición, el despojo, los desplazamientos forzados y los repoblamientos en el territorio que al parecer fueron proyectados para el mercadeo y consumo, exacerbado la crisis civilizatoria y generando grandes concentraciones de población urbana en pequeñas o inadecuadas zonas para la vida en dignidad. (Insuasty Rodriguez \& Vallejo Duque, Crar Ambiente para la Paz, 2012)

El orden autoritario administrador de la guerra se reviste como factor de desarrollo, promocionando una sensación de seguridad y de terror a partir del estado de opinión 
y el chantaje mediático vendiendo una guerra de odios, en el ánimo de legitimar el orden represivo de la doble moral burguesa conservadora que desde siempre acompaña el imaginario colectivo de la seudo cultura mercenaria. De alli emergen nuevas elites politicas: militares, paramilitares y mafias asociadas al narcotráfico, que administran las instituciones y la justicia para sí.

La crisis humanitaria que padece nuestro contexto inmediato, no es asumida por la sociedad en su conjunto y obviamente las formas para-institucionales sacan provecho. El hacer de los procesos politicos de cambio, anda en la encrucijada y su fuerza se diluye en las coyunturas propuestas por la realidad del esquema que impera y no deja trascender las luchas periféricas por resolver las necesidades básicas y alcanzar las garantías sociales anheladas en la ilustración. Aunque se sabe que la contienda guerrera no será la que resuelva estas grandes heridas que vienen desde la época de la conquista, un representativo sector de la sociedad la sigue justificando y promoviendo como solución.

Las consecuencias para la población en general van en aumento, llevando la peor parte los sectores de las desventajas históricas que son las mayorias explotadas, desposeídas, y excluidas socialmente, sometidas al orden de la injusticia, que la guerra re-victimiza, estigmatizando, despojando, desplazando persiguiendo y eliminando. Al colocarse en la situación de los sujetos concretos que padecen la guerra y sus voces de subalternidad, se adquiere conciencia que en las condiciones bélicas, las comunidades tímidamente pueden organizarse, pronunciar su voz y participar de la vida política, retomando el propio proyecto de vida y de comunidad.

\section{Conclusiones.}

Proyectar el final de este último ciclo de conflicto político armado y empezar a transformar la vivencia guerrera de 50 años implica entender, que se deben intervenir imaginarios poblacionales posicionados en dicho acontecimiento histórico, pues por un lado están quienes no quieren acabarla porque sienten que se pone en riesgo la propiedad privada, temen se modifiquen sus privilegios e intereses individuales acumulados, asunto que pareciera no puede ponerse en debate, ni siquiera para pensar en regular las leyes que generan tal desventaja y desequilibrio. Tocar este punto es tocar la verdadera causa de la exclusión social no posibilitar el bien común y apuntar a la propiedad colectiva.

Un segundo imaginario tiene que ver con el odio acumulado de los mega propietarios afectados en la contienda, sobre todo las familias latifundistas que tienen poder o como influir en él. Y un tercer imaginario es el proyecto de vida a partir de la guerra, las industrias militares, los especuladores nacionales de la guerra, el mercenarismo que emerge del aprovechamiento de la exclusión social y la miseria. Pequeños enclaves económicos que han emergido de la condición social del combate y la zozobra, en el que las relaciones humanas entre pobladores se rigen por el sálvese quien pueda y a como dé lugar, pero la contienda se mantiene, mientras sea negocio.

La lectura de la realidad contextual en clave de las relaciones de dominación, la caracterización de las violencias y sus causas de exclusión social y política, las 
condicionantes cada vez más adversas de la dinámica socio-económica, no nos dejan pensar de forma optimista. Entendiendo que la violencia no es única, ni tiene una sola causa y una manera de agenciarse. La pregunta será la de siempre ¿Cómo nos preparamos para tener mejores conflictos? ¿Cómo desarrollar la capacidad de aprovechar la negociación como medio para instituir procesos políticos?

Los movimientos sociales siempre han estado buscando alternativas de solución y respuestas a la restringida democracia del país y lo han hecho tratando de configurarse desde poderes alternos y paralelos, que obliguen a las hegemonias a posibilitar la participación comunitaria y popular, concediendo espacios y aceptando muchas de sus propuestas como parte del proceso de relegitimación de los poderes existentes.

Colocándonos en contexto durante el largo trayecto que va desde que inició la última gran guerra en Colombia, de manera manifiesta, un sin número de movilizaciones y concentraciones que ha recogido la multiplicidad de expresiones de pobladores en las vías de las ciudades y los campos buscado ser escuchados en su lucha por un pacto social que les incluya. En Colombia la paz de los pueblos reclama que le dejen tejer vida digna, derechos, tierras, viviendas y posibilidades de que la vida perdure como colectividad en relación de equilibrio eco sistémico.

Los movimientos y organizaciones tienen como posibilidad generar una coyuntura crítica, que obligue a los poderes instituidos y hegemónicos, al reconocimiento de las voces desde abajo, como sujetos de una misma comunidad politica, que no tienen que eliminarse para generar un logro político. La movilización social como la reserva democrática y su noción de paz, como agente importante de la política de acción, de la voluntad deliberada y la autonomía de los ciudadanos, es la única fuerza con capacidad para desactivar la guerra. Se necesitan echar a andar como pueblo acciones deliberadas sobre como resguardar el umbral de derechos y asegurar la integración social de la mayoría, como enfrentar la restricción neoliberal y promover una economía de redistribución de la riqueza para preservar la construcción y el sentido de la pertenencia a un proceso en el, el de la paz de los pueblos, que nos permite pensar el derecho que tienen los pueblos a que les dejen vivir en paz, auto-organizándose y construyendo planes de vida en sus territorios.

La apertura de ciertos espacios para la participación popular en la negociación y el trámite de los conflictos como medio de recuperar legitimidad, será un proceso que demandara tiempo y capacidad creativa. De manera que las organizaciones, que actúen movidos hacia intereses colectivos para defender los bienes comunes y generen el escenario apropiado para la transformación de las condiciones políticas y sociales.

En la comprensión de la realidad del conflicto y el post conflicto entendido como una sociedad mejor que la que tenemos, empezará cuando se reconozcan las dificultades para tramitar los conflictos, la ausencia de cultura política y la incapacidad de negociación política. Se realza la importancia de cualificar el pensamiento y la cultura politica para la posibilidad, desde iniciativas organizativas y formativas que recojan las capacidades y esperanzas, que se han ido acumulando en los procesos de resistencia a las relaciones socio-económicas y culturales de dominación ejercidas desde la institucionalidad. Buscando que la conciencia active 
los valores necesarios para superar las relaciones de dominación en el escenario de las prácticas sociales. La apropiación crítica y autocrítica de las propias prácticas politicas y comunitarias.

Esta implica el desarrollo de acciones que busquen que las colectividades logren el reconocimiento de su propia experiencia de transformación organizativa y la proyección de su praxis política en la adversidad de los contextos y territorios donde accionan. Esa autoproducción de la historicidad es un rasgo esencial hacia el cambio de la propia historia, personal, colectiva y organizativa como nación. Los procesos de memoria histórica, las comisiones de verdad y la sistematización de las experiencias son herramientas que en la coyuntura de la generación política generaran los argumentos e intenciones a partir de coordinar prácticas y discursos organizativos con vocación de transformación hacia la construcción de poder, Sin perder de vista la posibilita de los sujetos participantes y el reconocimiento de su propia experiencia de transformación 


\section{Referencias Bibliográficas.}

Alain, T. (1987). Actores sociales y sistemas politicos en América Latina. Buenos Aires: Prealc.

Arcila, M., \& Pardo, M. (2001). Movimientos sociales, estado y democracia en Colombia. Bogotá: Universidad Nacional de Colombia.

Boff, L. (2012). La tierra no aguanta mas. Recuperado el 15 de 2 de 2014, de rebelion. com: http:/ / www.rebelion.org/noticia.php?id=94809

Boff, L. (07 de 03 de 2014). La gestación del pueblo brasilero, la universidad y el saber popular. Obtenido de servicioskoinonia.org: http://www.servicioskoinonia.org/ boff/articulo.php?num=624

Borda, F., Umaña, L., \& Guzman, C. (2012). La violencia en Colombia. Tomo I. Bogotá: Prisa Ediciones.

Boron, A. (2004). Estado, capitalismo y democracia en América Latina. Quito (Ecuador): Clacso.

De Sousa Santos, B. (20 de Marzo de 2000). Reinventar la democracia. Recuperado el 24 de Septiembre de 2014, de Boaventuradesousasantos.pt: http://www. boaventuradesousasantos.pt/media/reinventar-la-democracia.pdf

Escobar, A., Alvarez, S., \& Dagnino, E. (2001). Politica cultural, cultura politica. Una nueva mirada sobre los movimientos sociales latinoamericanos. Bogotá: Taurus.

García Duran, M. (2004). Colombia: retos y dilemas en la búsqueda de la Paz. Controversia, 4-9.

García, A. (1977). Colombia: esquema de una república señorial. Bogotá: Cruz del Sur.

González Bombal, I. (1998). Hacia un nuevo contrato social para el Siglo XXI. Buenos Aires: Banco Interamericano del Desarrollo. Obtenido de http://opac.uncoma. edu.ar/cgi-bin/koha / opac-detail.pl?biblionumber=24037\&shelfbrowse itemnumber $=47452$

Gramsci, A. (2000). Los intelectuales y la organización cultural. Buenos Aires: Nueva Visión.

Insuasty Rodriguez, A. (2010). Solos no podemos. Editorial. Revista Kavilando, 4-8.

Insuasty Rodriguez, A., \& Vallejo Duque, Y. (2012). Crar Ambiente para la Paz. Kavilando, 11-18.

Insuasty Rodriguez, A., Grisales Grajales, D., \& Gutierrez Leon, E. M. (30 de Diciembre de 2013). Conflictos asociados a la gran mineria en Antioquia. El Agora USB, 13(2), 371-397. Obtenido de http://web.usbmed.edu.co/usbmed/elagora/ $\mathrm{htm} / \mathrm{v} 13 \mathrm{nro}$ /pdf/CONFLICTOS-ASOCIADOS-A-LA-GRAN-MINERIA.pdf 
Monsivais, C., \& Poniatowska, E. (1997). Policial Science, EZLN. Mexico: Era.

Morin, E. (Mayo de 1995). Fronteras de lo politico. Revista de Occidente(168), 15.

Morin, E. (1998). Civilización. Madrid: Tendencias Siglo XXI.

Movimiento de los Trabajadores Rurales sin Tierra. (2013). Programa Agrario del MST. Alameda Barao de Limeira, Sao Paulo: SP. Edición.

Restrepo Dominguez, M. (20 de Marzo de 2014). Democracia de Mercado: Enfermos y Hacinados Negocio Exitoso. Obtenido de kavilando.org: http: / www.kavilando. org/index.php/2013-10-13-19-52-10/formacion-popular/2631-democraciade-mercado-enfermos-y-hacinados-negocio-exitoso

Restrepo Marin, J. (2013). Crisis del capital y movilizaciones sociales. Kavilando, 5(1), 45-50. Obtenido de http://revistakavilando.weebly.com/ uploads /1/3/6/3/13632409/crisis_y_movimiento_sociales_rkv5n1.pdf

Restrepo Rodriguez, M. H. (20 de Marzo de 2014). Democracia de Mercado. Obtenido de Kavilando.org: http://www.kavilando.org/index.php/2013-10-13-19-5210 /formacion-popular/2631-democracia-de-mercado-enfermos-y-hacinadosnegocio-exitoso

Rodriguez Dominguez, H. (9 de Diciembre de 2014). Democracia sin politica. Recuperado el 9 de diciembre de 2014, de kavilando.org: http:/ /www.kavilando. org/index.php/2013-10-13-19-52-10/formacion-popular/3174-democraciassin-politica

Vega Cantor, R. (02 de 04 de 2009). Crisis civilizatoria. Recuperado el 02 de 02 de 2012, de www.prensarural.org: http://prensarural.org/spip/spip. php?article 2197

Vega Cantor, R. (2013). Colombia y geopolicia hoy. El Agora USB, 367-402.

Zibechi, R. (2000). La mirada Horizontal: movimiento sociales y emancipación. Quito: Abya Yala. 